\title{
N-PROTEIN KINASE C ISOENZYMES MAY BE INVOLVED IN THE REGULATION OF VARIOUS NEUTROPHIL FUNCTIONS
}

Katharina Wenzel-Seifert ${ }^{1}$, Christoph Schächtele ${ }^{2}$ and Roland Seifert ${ }^{{ }^{*}}$

1 Institut für Pharmakologie, Freie Universität Berlin, Thielallee 69-73, D-14195 Berlin, Germany

2 Institut für Molekulare Medizin und Naturstofforschung, Klinik für Tumorbiologie, Breisacherstr. 117, D-79106 Freiburg, Germany

Received March 9, 1994

The role of protein kinase $C$ (PKC) isoenzymes in the regulation of cell functions is largely unknown. We studied the effects of 2-(1H-indol-3-yl)-3[1-(3-dimethylaminopropy 1)-1H-indo1-3-yl]-maleinimide (Gö 6850), a selective inhibitor of $c-$ and n-PKC isoenzymes, and 12-(2-cyanoethy 1$)-6,7,12,13-$ tetrahydro-13-methy $1-5-0 \times 0-5 \mathrm{H}-$ indolo $[2,3-a]$ pyrrolo[3,4-c]-carbazole (Gö 6976), an inhibitor of c-PKC isoenzymes, on various human neutrophil functions. Gö 6850 inhibited $4 \beta$-phorbol 12-myristate 13-acetate (PMA)-, 1,2-dicaprylylglycerol- and chemotactic peptide-induced superoxide anion formation with half-maximal effects at $100 \mathrm{nM}, 240 \mathrm{nM}$ and $850 \mathrm{nM}$, respectively. Gö 6850 reverted PMA-mediated inhibition of chemotactic peptide-induced rises in cytosolic $\mathrm{Ca}^{2+}$ concentration with a half-maximal effect at $480 \mathrm{nM}$. Gö 6850 (1 $\left.\mu \mathrm{M}\right)$ inhibited PMA-induced lysozyme release by $55 \%$. Gö 6976 had no effect on the parameters studied. Our data suggest the following: (1) $n$-Rather than C-PKC isoenzymes are involved in the regulation of various human neutrophil functions. (2) Different $n-P K C$ isoenzymes may mediate activation of NADPH oxidase by various stimuli. (3) Different $n$-PKC isoenzymes may be involved in the mediation of the effects of PMA on various cell functions. 1994 Academic Press, Inc.

Numerous intercellular signal molecules induce activation of phospholipase $C$ which catalyzes the degradation of phosphatidylinositol-4,5-bisphosphate to DG and 1,4,5-trisphosphate [for review see Ref. 1]. DG activates PKC which plays an inportant role in mediation of the effects of intercellular

* To whom correspondence should be addressed.

ABBREVIATIONS:

$\left[\mathrm{Ca}^{2+}\right]_{1}$ cytosolic $\mathrm{Ca}^{2+}$ concentration; DCG, 1,2-dicaprylylglycerol; DG, 1,2diacylglycerol; DMSO, dimethyl sulfoxide; FMLP, $N$-formy $1-L$-methionyl-Lleucyl-L-phenylalanine; Gö 6850, 2-(1H-indol-3-y1)-3-[1-(3-dimethylaminopropy1)-1H-indol-3-yl]-maleinimide; Gö 6976, 12-(2-cyanoethyl)-6,7,12,13-tetrahydro-13-methyl-5-oxo-5H-indolo[2,3-a]pyrrolo[3,4-c]-carbazole; IC $\mathrm{C}_{50}$ concentration of a substance causing $50 \%$ of maximal inhibition; $0_{2}^{-}$, superoxide anion; PMA, 4ß-phorbol 12-myristate 13-acetate; PKC, protein kinase $C$.

0006-291X/94 \$5.00

Copyright (C) 1994 by Academic Press, Inc

All rights of reproduction in any form reserved. 
signal molecules [for review see Refs. 2 and 3]. The tumor promotor, PMA, is also a PKC activator [4].

PKC is not a single enzyme but a superfamily of three isoenzyme families with several members each [2-4]. C-PKC isoenzymes $(\alpha, \beta 1, \beta 2$ and $\gamma)$ are $\mathrm{Ca}^{2+}$-dependent and are activated by $\mathrm{DG}$ and PMA. $n-P K C$ isoenzymes $(\delta, \varepsilon, \eta$ and A) are $\mathrm{Ca}^{2+}$-independent but activated by DG and PMA. a-PKC isoenzymes ( $\lambda$ and ()) are $\mathrm{Ca}^{2+}$-independent and are not activated by DG and PMA.

Little is known about the role of PKC isoenzymes in the regulation of cell functions [2-4]. One of the reasons for this paucity of knowledge has been the non-availability of isoenzyme-specific PKC inhibitors [for review see Ref. 5]. Recently, PKC inhibitors with some selectivity for PKC isoenzymes have been developed. The bisindolylmaleinimide, Gö 6850 (also referred to as GF 109203X [7]), inhibits recombinant PKC isoenzymes $\alpha$ and $\beta 1$ with $I_{50}$ values of $8.4 \mathrm{nM}$ and $18 \mathrm{nM}$, respectively, and $P K C$ isoenzymes $\delta$ and $E$ are inhibited with $\mathrm{IC}_{50}$ values of $210 \mathrm{nM}$ and $132 \mathrm{nM}$, respectively [6]. The $\mathrm{IC}_{50}$ of Gö 6850 for recombinant PKC isoenzyme $\zeta$ is $5.8, \mu M$ [6]. The indolocarbazole, Gö 6976, inhibits recombinant PKC isoenzymes $\alpha$ and $B 1$ with $I_{50}$ values of $2.3 \mathrm{nM}$ and $6.2 \mathrm{nM}$, respectively, but it does not inhibit PKC isoenzymes $\delta, \varepsilon$ and $\zeta$ [6]. Thus, Gö 6850 and Gö 6976 could provide valuable tools to analyze the specific roles of $\mathrm{c}$ - and $\mathrm{n}$-PKC isoenzymes in the regulation of cell functions.

Human neutrophils possess $c$ - and n-PKC isoenzymes [8]. In these cells, PKC stimulation may lead to activation of $\mathrm{NADPH}$ oxidase-catalyzed $\mathrm{O}_{2}^{-}$formation and lysozyme release from specific granules and inhibition of chemotactic peptide-induced rises in $\left[\mathrm{Ca}^{2+}\right]_{j}[9-11]$. The role of $c$ - and $n-P K C$ isoenzymes in these functions is poorly defined. Therefore, we studied the effects of Gö 6850 and Gö 6976 on human neutrophil activation. Here, we present evidence in forward the notion that $n$ - rather than C-PKC isoenzymes are involved the regulation of various neutrophil functions.

\section{MATERIALS AND METHODS}

Gö 6850 and Gö 6976 were kindly provided by Gödecke AG (Freiburg, Br. Germany). Stock solutions of Gö 6850 and $G 0 ̈ 6976$ (1 $\mathrm{mM}$ each) were prepared in DMSO and stored at $-20^{\circ} \mathrm{C}$. Dilutions of Gö 6850 and Gö 6976 were prepared in distilled water fresh daily. DCG was obtained from Sigma Chemie (Deisenhofen, Germany). Sources of other materials have been described elsewhere [12-14].

Neutrophils were isolated from fresh blood of healthy volunteers [13]. Cell preparations consisted of more than $95 \%$ viable neutrophils as revealed by trypan blue dye exclusion. HL-60 cells were cultured and differentiated with DMSO as described [12]. HL-60 membranes and HL-60 cytosol were prepared according to Seifert and Schultz [12].

$\mathrm{O}_{2}^{-}$formation in intact cells was monitored at $550 \mathrm{~nm}$ by continuous measurement of ferricytochrome $C$ reduction inhibitable by superoxide dismutase, using an Uvikon 810 dual beam spectrophotometer (Kontron, Eching, Ger- 
many) [13]. Reaction mixtures $(0.5 \mathrm{ml})$ contained $100, \mathrm{M}$ ferricytochrome $\mathrm{C}$ and a buffer consisting of (mM) $138 \mathrm{NaCl}_{2} 6 \mathrm{KCl}, 1 \mathrm{MgCl}_{2}, 1 \mathrm{CaCl}_{2}, 5.5 \mathrm{glucose}$ and $20 \mathrm{Hepes} / \mathrm{NaOH}$, pH 7.4. Neutrophils $\left(1.0 \times 10^{6}\right.$ cells/cuvette) were suspended in the solution described above and were incubated for $3 \mathrm{~min}$ in the presence of various substances at $37^{\circ} \mathrm{C}$ before the addition of stimuli. In case of stimulation with FMLP, cytochalasin B $(1 \mu \mathrm{g} / \mathrm{ml})$ was added to cells 3 min before the chemotactic peptide.

$0_{2}^{-}$formation in a cell-free system was monitored by continuous measurement of ferricytochrome $\mathrm{C}$ reduction inhibitable by superoxide dismutase [12]. Reaction mixtures $(0.5 \mathrm{ml})$ contained $50 \mu \mathrm{g}$ of membrane protein and $150 \mu \mathrm{g}$ of cytosolic protein of $H L-60$ cells, $10 \mu M$ FAD, $500 \mu M$ NADPH, $100 \mu M$ ferricytochrome $\mathrm{C}_{1} 2 \mathrm{mM} \mathrm{MgCl}_{2}, 20 \mathrm{mM} \mathrm{KH}_{2} \mathrm{PO}_{4}, 40 \mathrm{mM} \mathrm{KCl}$ and $20 \mathrm{mM}$ triethanolamine/HC1, $\mathrm{pH}$ 7.4. Reaction mixtures were incubated for $2 \mathrm{~min}$ at 25 ${ }^{\circ} \mathrm{C}$ in the absence or presence of $\mathrm{Gö} 6850 . \mathrm{O}_{2}^{-}$formation was initiated by the addition of arachidonic acid $(200 \mu \mathrm{M})$.

$\left[\mathrm{Ca}^{2+}\right]$; was determined as described [14]. Briefly, neutrophils were suspended at $5^{i} \times 10^{6} \mathrm{cells} / \mathrm{ml}$ in a buffer consisting of (mM) $138 \mathrm{NaCl}, 6 \mathrm{KCl}, 1$ $\mathrm{MgSO}_{1}, 1.1 \mathrm{CaCl}_{2}, 0.1$ EGTA, $1 \mathrm{Na}_{2} \mathrm{HPO}_{4}, 5 \mathrm{NaHCO}_{3} 5.5$ glucose, and $20 \mathrm{He}-$ pes/NaOH, pH 7.4, supplemented with $0.1 \%(\mathrm{w} / \mathrm{v})$ bovine serum albumin. Cells were incubated for $1 \mathrm{~h}$ at $37^{\circ} \mathrm{C}$ in the presence of Fura-2 acetoxymethylester $(4, M)$. Subsequently, cells were diluted with the above buffer to a concentration of $0.5 \times 10^{6}$ cells $/ \mathrm{ml}$ and were centrifuged at $250 \times \mathrm{g}$ for $10 \mathrm{~min}$ at $20^{\circ} \mathrm{C}$. Cells were suspended at $2.0 \times 10^{6} \mathrm{cell} / \mathrm{s} / \mathrm{ml}$ in the above buffer and were kept at $20{ }^{\circ} \mathrm{C}$ until measurement of $\left[\mathrm{Ca}^{2+}\right]_{\mathrm{i}}$. Fluorescence of neutrophils $(1.0 \mathrm{x}$ $10^{6} \mathrm{cel}(\mathrm{s} / \mathrm{ml})$ was determined at $37{ }^{\circ} \mathrm{C}$ using a Ratio II spectrofluorometer (Aminco, Silver Spring, MD, USA). Cells were incubated for 6 min in the presence of various substances before the addition of FMLP. Excitation and emission wavelengths were $340 \mathrm{~nm}$ and $500 \mathrm{~nm}$, respectively.

The release of lysozyme from human neutrophils was determined according to Seifert et al. [13]. Neutrophils $\left(5 \times 10^{6}\right.$ cells in $\left.0.5 \mathrm{ml}\right)$ were incubated for $5 \mathrm{~min}$ in the presence of cytochalasin B $(1 \mathrm{~kg} / \mathrm{ml})$ and various substances in the buffer used for determination of $\mathrm{O}_{2}^{-}$formation in intact cells. At 10 min after addition of solvent (basal release) or PMA, tubes were cooled to 4 ${ }^{\circ} \mathrm{C}$ and were centrifuged for $10 \mathrm{~min}$ at $250 \times \mathrm{g}$. Determination of the activities of lysozyme and lactate dehydrogenase in the supernatant fluids of reaction mixtures and cell lysates was performed as described [13].

\section{RESULTS}

The effects of Gö 6850 and Gö 6976 on human neutrophil $\mathrm{O}_{2}{ }^{-}$formation activated by various stimuli at maximally effective concentrations are summarized in Fig. 1. Gö 6850 inhibited PMA-induced $\mathrm{O}_{2}{ }^{-}$formation with an $\mathrm{IC}_{50}$ of $100 \mathrm{nM}$ and a maximum at $500 \mathrm{nM}$. With respect to $\mathrm{O}_{2}{ }^{-}$formation induced by the cell-permeant $D G, D C G$, the $I_{50}$ of $G 006850$ amounted to $240 \mathrm{nM}$, and its inhibitory effect was complete at $3 \mu \mathrm{M}$. Gö 6850 inhibited $\mathrm{O}_{2}^{-}$formation induced by the chemotactic peptide, FMLP, with an $I_{50}$ of $850 \mathrm{nM}$ and a maximum at $3 \mu M$. Gö 6976 did not inhibit or only marginally reduce $\mathrm{O}_{2}^{-}$formation, regardless of whether stimuli were employed at maximally effective concentrations (see Fig. 1) or at submaximally effective concentrations (data not shown). In a cell-free system consisting of membranes and cytosol of HL-60 cells and arachidonic acid, Gö 6850 up to $3 \mu \mathrm{M}$ did not inhibit $\mathrm{O}_{2}^{-}$formation (data not shown), indicating that the substance did not act as radical scavenger or direct inhibitor of NADPH oxidase. 


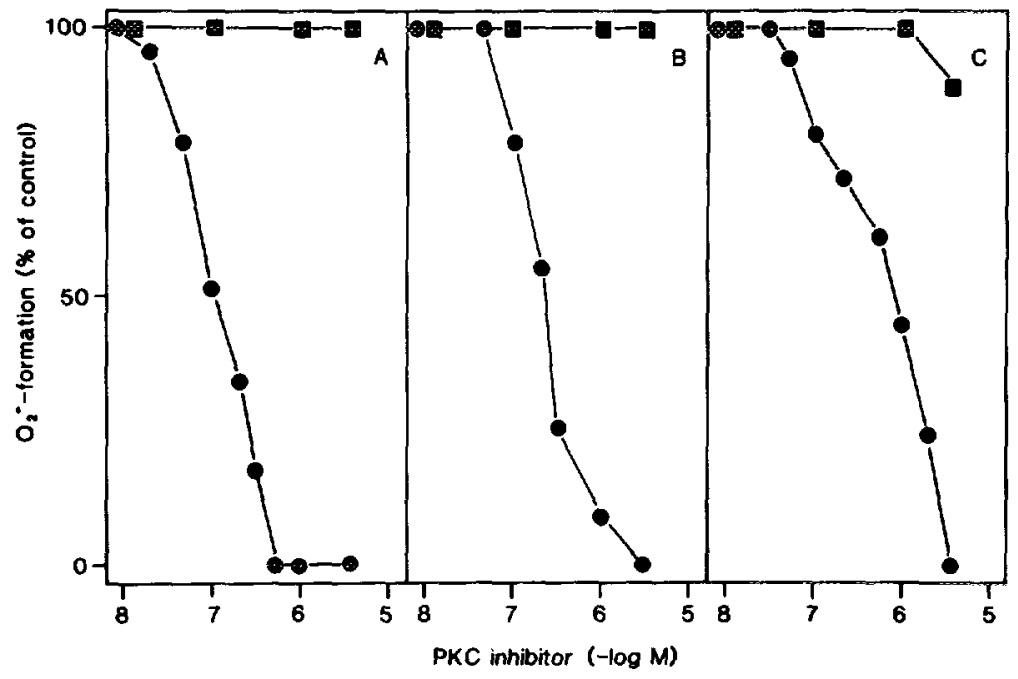

Fig. 1. Effects of Gö 6850 and Gö 6976 on $\mathrm{O}_{2}^{-}$formation in human neutrophils. $\mathrm{O}_{2}^{-}$formation was determined as described in "Materials and Methods". $0_{2}^{2}$ - formation was activated by PMA (100 nM) (A), OCG (100 /M) (B) or FMLP (1 MM) plus cytochalas in $B(1 \mu \mathrm{g} / \mathrm{ml})$ (C). Under control cond $i$ tions, PMA, DCG and FMLP plus cytochalasin B induced the formation of $10.5 \pm 0.5,8.6 \pm 0.9$ and $6.6 \pm 0.5 \mathrm{nmol}$ of $0_{2}^{-} / 10^{6} \mathrm{cell} / \mathrm{s} / \mathrm{min}$ (means \pm SD, $\mathrm{n}=3-6$ ), respectively. Gö 6850 ( O ) and Gö 6976 ( $)$ ) were added to cells at the indicated concentrations 3 min before stimuli. Data shown are referred to $\mathrm{O}_{2}^{-}$formation under control conditions and are the means of 3-6 experiments performed with neutrophils from different donors. The SD values were generally $<10 \%$ of the means.

Time courses of FMLP-induced rises in $\left[\mathrm{Ca}^{2+}\right]_{j}$ are shown in Fig. 2. Under control conditions, FMLP induced a rapid increase in $\left[\mathrm{Ca}^{2+}\right]_{j}$ which, after an initial peak, declined to a plateau above basal values. Pretreatment with PMA (100 nM) abolished the stimulatory effect of FMLP $(3 \mathrm{nM})$ on $\left[\mathrm{Ca}^{2+}\right]_{j}$. Gö 6850 and Gö 6976 per se had no effect on FMLP-induced rises in $\left[\mathrm{Ca}^{2+}\right]_{i}$, but Gö $6850(1 \mu M)$ reverted the inhibitory effect of PMA on this parameter. The reverting effect of Gö 6850 on PMA-mediated inhibition of FMLP-induced rises in $\left[\mathrm{Ca}^{2+}\right]_{i}$ was half-maximal at $480 \mathrm{nM}$ (Fig. 3). By contrast to Gö 6850, Gö $6976(1, M)$ did not revert the inhibitory effect of PMA (see Fig. 2). The effect of Gö 6976 at higher concentrations on $\left[\mathrm{Ca}^{2+}\right]_{i}$ could not be studied due to strong autofluorescence of the substance (data not shown).

The effects of Gö 6850 and Gö 6976 on enzyme release in neutrophils were also studied. Gö 6850 and Gö 6976 per se did not stimulate lysozyme release (Table 1) and lactate dehydrogenease release (data not shown), indicating that they were not cytotoxic at the concentrations applied. PMA at a maximally effective concentration increased lysozyme release by $30 \%$ of the cellular content (see Table 1). Gö 6850 (1 lM) reduced this stimulatory effect of PMA by 55\%, whereas Gö 6976 (1 lM) had no inhibitory effect. 


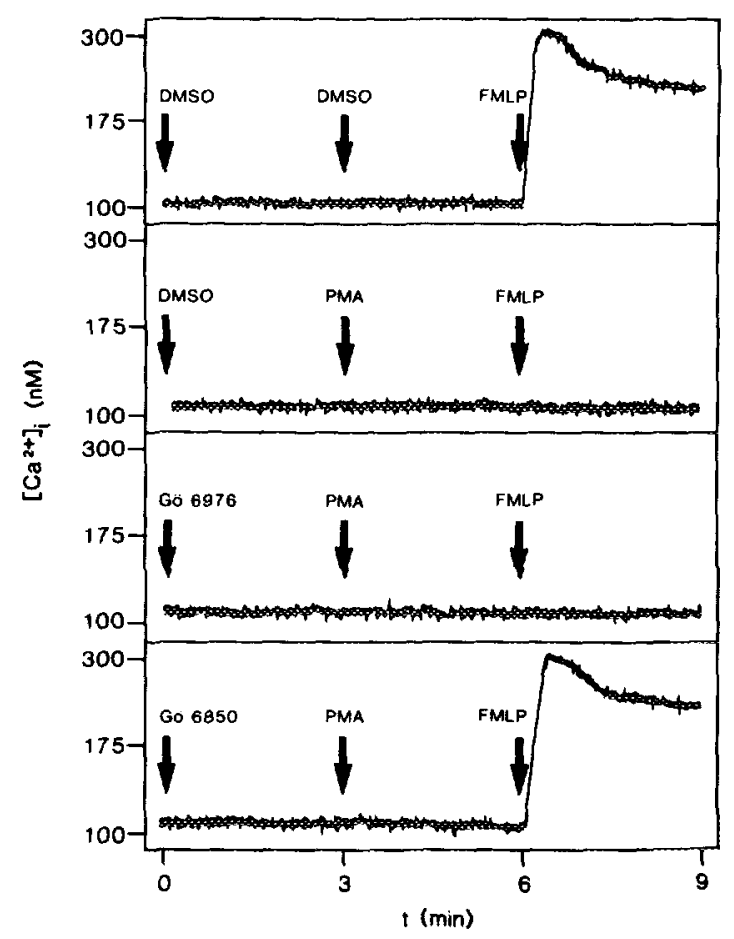

Fig. 2. Effects of PMA, Gö 6850 and Gö 6976 on FMLP-induced rises in $\left[\mathrm{Ca}^{2+}\right]_{j}$ in human neutrophils. [Ca $\left.{ }^{2+}\right]$ was determined as described in "Materials and Methods". Arrows indicate the addition of OMSO $(0.1 \%$, $v / v)$, PMA (100 nM), Gö 6850 (1 , M), Gö 6976 (1 , M ) and FMLP (3 nM), respectively. Original fluorescence tracings are shown. Similar results were obtained in three experiments performed with neutrophils from different donors.

\section{DISCUSSION}

Gö 6850, an inhibitor of $c-$ and $n-P K C$ isoenzymes [6], effectively inhibits $\mathrm{O}_{2}{ }^{-}$formation induced by various stimuli and PMA-induced lysozyme release and reverts PMA-mediated inhibition of FMLP-induced rises in $\left[\mathrm{Ca}^{2+}\right]_{i}$ in human neutrophils. By contrast, Gö 6976, a selective inhibitor of c- but not of n-PKC isoenzymes [6], showed no or almost no effect in neutrophils. The lack of effectiveness of Gö 6976 is unlikely due to poor penetration of the substance through the plasma membrane as it is highly lipaphilic [6]. In addition, the concentrations of Gö 6976 employed in our present experiments were up to 1300 -fold higher than those required for half-maximal inhibition of C-PKC isoenzymes in vitro [6]. Moreover, Gö 6976, at concentrations similar to those employed by us, showed substantial inhibitory effects in various bone marrow-derived cell types $[15,16]$. Furthermore, Gö 6850 is also very lipophilic [7], but its potency to inhibit $0_{2}^{-}$formation and to revert the inhibitory effect of PMA on $\left[\mathrm{Ca}^{2+}\right]_{j}$ is 5 - to 100 -fold lower than the one to 


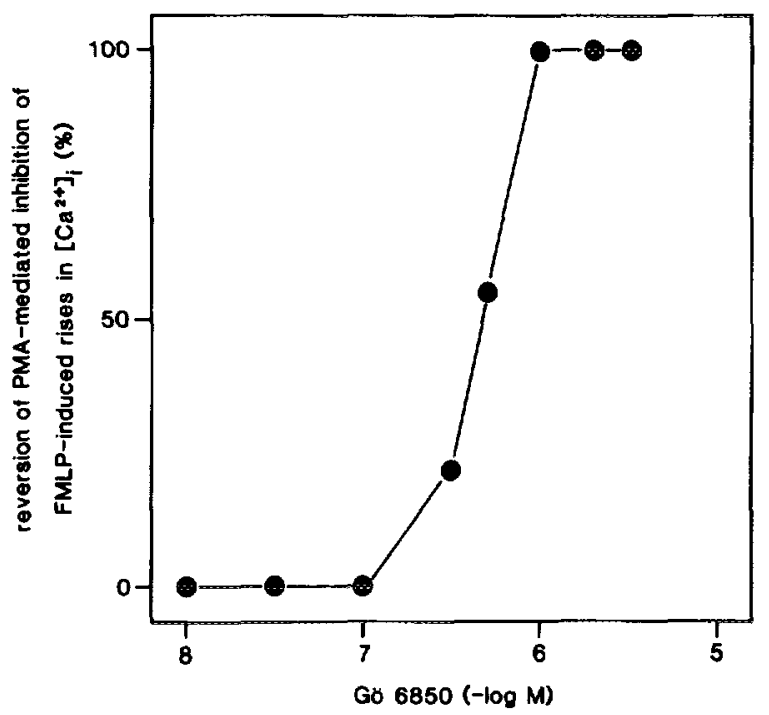

Fig. 3. Reversion by Gö 6850 of PMA-mediated inhibition of FMLP-induced rises in $\left[\mathrm{Ca}^{2+}\right]_{j}$ in human neutrophils: Concentration/response for Gö 6850 . $\left[\mathrm{Ca}^{2+}\right]$ was determined as described in "Materials and Methods". The order of addition of DMSO $(0.1 \%, v / v), G 0 ̈ 6850$ at various concentrations, PMA (100 nM) and FMLP (3 nM) was performed as shown in Fig. 2. Under control conditions (two-fold addition of DMSO), FMLP increased $\left[\mathrm{Ca}^{2+}\right]$ by $199 \pm 21 \mathrm{nM}$ (means \pm SD, $\left.n=3\right)(100 \%)$. In the presence of PMA, FMLP did not induce a rise in $\left[\mathrm{Ca}^{2+}\right]_{1}(0 \%)$. The reverting effect of Gö 6850 on PMA-mediated inhibition of FMLP-induced rises in $\left[\mathrm{Ca}^{2+}\right]_{\text {, }}$ is referred to these values. Data shown are the means of three experiments performed with neutrophils from different donors. The SD values were generally $<10 \%$ of the means.

inhibit recombinant PKC isoenzymes $\alpha$ and 31 in vitro (see Figs. 1 and 3) [6]. Taken together, our data suggest that $n$ - rather than C-PKC isoenzymes are involved in the activation of NADPH oxidase and specific granule release and

Table 1: Effects of Gö 6850 and Gö 6976 on lysozyme release in human neutrophils

\begin{tabular}{lcc}
\hline Addition & \multicolumn{1}{l}{ lysozyme release $(\%$ of cellular content $)$} \\
\cline { 2 - 3 } & Basal & PMA $(100 \mathrm{nM})$ \\
\hline DMSO $(0.1 \%, v / v)$ & $9.5 \pm 0.4$ & $39.9 \pm 2.7$ \\
Gö 6850 $(1, \mathrm{M})$ & $9.6 \pm 0.7$ & $24.3 \pm 2.3$ \\
Gö 6976 $(1, \mathrm{M})$ & $8.5 \pm 1.8$ & $39.5 \pm 2.4$
\end{tabular}

Lysozyme release was determined as described in "Materials and Methods". Gö 6850, Gö 6976 or DMSO were added to cells 5 min before solvent (basal release) or PMA. Data shown are the means \pm SD of assay quadruplicates of a representative experiment. Similar results were obtained in three experiments with neutrophils from different donors. 
PMA-mediated inhibition of FMLP-induced rises in $\left[\mathrm{Ca}^{2+}\right]_{j}$ in human neutrophils. In agreement with our suggestion, Sharma et al. [17] reported that $n$ PKC isoenzymes are capable of activating $\mathrm{O}_{2}^{-}$formation in a cell-free system derived from murine macrophages. Future studies will have to be performed to answer the question what the function of C-PKC isoenzymes in human neutrophils may be.

Gö 6850 differentially inhibited PMA- and DCG-induced $\mathrm{O}_{2}^{-}$formation (see Fig. 1). Differences in the regulation of DG- and PMA-mediated activation of $\mathrm{O}_{2}{ }^{-}$formation have also been observed by other authors $[18,19]$. These findings may indicate that different $n$-PKC isoenzymes are involved in mediation of PMA- and DG-induced NADPH oxidase activation. Interestingly, the $\mathrm{IC}_{50}$ value of Gö 6850 for PMA-induced $\mathrm{O}_{2}^{-}$formation is similar to the one for PKC isoenzyme $\equiv$ in vitro (see Fig. 1) [6]. With respect to DCG-induced $\mathrm{O}_{2}{ }^{-}$formation, the $I_{50}$ of Gö 6850 is similar to the one for PKC isoenzyme $\delta$ in vitro (see Fig. 1) [6]. Thus, PKC isoenzymes $\cong$ and $\delta$ may mediate PMA- and DCG-induced $\mathrm{O}_{2}^{-}$formation, respectively, but further work is required to substantiate this hypothesis.

The potency of Gö 6850 to inhibit FMLP-induced $0_{2}^{-}$formation and to revert PMA-mediated inhibition of FMLP-induced rises in $\left[\mathrm{Ca}^{2+}\right]_{j}$ is lower than the one to inhibit PMA- and DCG-induced $\mathrm{O}_{2}{ }^{-}$formation and PKC isoenzymes $\delta$ and $\epsilon$ in vitro (see Figs. 1 and 2) [6]. Moreover, Gö 6850 at a concentration as high as $1 \mu$ M only partially inhibited the stimulatory effect of PMA on 1ysozyme release in neutrophils (see Table 1). These findings suggest that $n$-PKC isoenzymes distinct from PKC isoenzymes $\delta$ and $\lesssim$ are involved in FMLP-induced activation of NADPH oxidase, PMA-induced specific granule release and PMA-mediated inhibition of FMLP-induced rises in $\left[\mathrm{Ca}^{2+}\right]_{j}$. However, the $\mathrm{IC}_{50}$ values of Gö 6850 for the other n-PKC isoenzymes have not yet been determined.

With respect to FMLP-induced $\mathrm{O}_{2}^{-}$formation, we cannot exclude the possibility that an a-PKC isoenzyme is involved in NADPH oxidase activation. This PKC isoenzyme, however, should be distinct from PKC isoenzyme $\zeta$, as the $\mathrm{IC}_{50}$ of Gö 6850 for FMLP-induced $\mathrm{O}_{2}^{-}$formation is about 7-fold lower than for recombinant PKC isoenzyme $\zeta$ in vitro (see Fig. 1) [6].

In conclusion, $n$ - rather than C-PKC isoenzymes may be involved in the regulation of various neutrophil functions. Different $n-P K C$ isoenzymes may mediate activation of NADPH oxidase by various stimuli, and different $n-P K C$ isoenzymes may be involved in the mediation of the effects of PMA on various cell functions. Finally, our data show that Gö 6850 and Gö 6976 are valuable experimental tools to analyze the role of $c$ - and $n$-PKC isoenzymes in the regulation of cell functions.

ACKNOWLEDGMENTS: We thank Mrs. Evelyn Glaß for expert technical assistance. This work was supported by grants of the Deutsche Forschungsgemeinschaft. 


\section{REFERENCES}

1. Rhee, S. G., and Choi, K. D. (1992) J. Biol. Chem. 267, 12393-12396.

2. Asaoka, Y., Nakamura, S., Yoshida, K., and Nishizuka, Y. (1992) Trends Biochem. Sci. 17, 414-417.

3. Hug, H., and Sarre, T. F. (1993) Biochem. J. 291, 329-343.

4. Castagna, M., Takai, Y., Kaibuchi, K., Sano, K., Kikkawa, U., and Nishizuka, Y. (1982) J. Biol. Chem. 257, 7847-7851.

5. Wilkinson, S. E., and Hallam, T. J. (1994) Trends Biochem. Sci. 15, 5357 .

6. Martiny-Baron, G., Kazanietz, M. G., Mischak, H., Blumberg, P. M., Kochs, G., Hug, H., Marmé, D., and Schächtele, C. (1993) J. Biol. Chem. 268, 9194-9197.

7. Toullec, D., Pianetti, P., Coste, H., Bellevergue, P., Grand-Perret, T., Ajakane, M., Baudet, V., Boissin, P., Boursier, E., Loriolle, F., Duhamel, L., Charon, D., and Kirilorsky, J. (1991) J. Biol. Chem. 266, 1577115781 .

8. Majumdar, S., Kane, L. H., Rossi, M. W., Volpp, B. D., Nauseef, W. M., and Korchak, H. M. (1993) Biochim. Biophys. Acta 1176, 276-286.

9. Kang, D., Tsuda, H., Takeshige, K., Shibata, Y., and Minakami, S. (1985) J. Biochem. 98, 1699-1706.

10. Seifert, R., and Schultz, G. (1991) Rev. Physiol. Biochem. Pharmacol. $117,1-338$

11. Schöndorf, M., Bidlingmaier, F., and von Ruecker, A. A. (1993) Biochem. Biophys. Res. Commun. 197, 549-555.

12. Seifert, R., and Schultz, G. (1987) Biochem. Biophys. Res. Commun. 146, 1296-1302.

13. Seifert, R., Schultz, G., Richter-Freund, M., Metzger, J., Wiesmüller, K.-H., Jung, G., Bessler, W.G., and Hauschildt, S. (1990) Biochem. J. $267,795-802$.

14. Seifert, R., Höer, A., Offermanns, S., Buschauer, A., and Schunack, W. (1992) Mol. Pharmacol. 42, 227-234.

15. Qatsha, K. A., Rudolph, C., Marmé, D., Schächtele, C., and May, W. S. (1993) Proc. Nat1. Acad. Sci. USA 90, 4674-4678.

16. Höer, A., Höer, D., Oberdisse, E., and Schultz, G. (1994) Naunyn-Schmiedeberg's Arch. Pharmacol. 349 (Suppl.) (in press).

17. Sharma, P., Evans, A. T., Parker, P. J., and Evans, F. J. (1991) Biochem. Biophys. Res. Commun. 177, 1033-1040.

18. Bonser, R. W. Dawson, J., Thompson, N. T., Hodson, H. F., and Garland, L. G. (1986) FEBS Lett. 209, 134-138.

19. Badwey, J. A., Robinson, J.M., Heyworth, P. G., and Curnutte, J. T. (1989) J. Biol. Chem. 264, 20767-20682. 